\title{
Vertical ridge augmentation in posterior mandible - Case report
}

\section{Silva $L^{1}$}

Affiliations:

1. University Specialist in Implant dentistry at Santiago de Compostela University School

of Medicine and Dentistry, in Santiago de

Compostela; Oral Surgery Specialist by

Portuguese Dental Association; Private Practice

in Oral Surgery and Implant Dentistry, Porto

(Portugal).

Corresponding author:

Liliana Silva

liafsilva@gmail.com

\section{ABSTRACT}

Purpose: This clinical case describes a successful use of a non-resorbable membrane and mixture of autogenous particulated bone with anorganic bovine bone-derived mineral (ABBM) in a severe posterior mandible alveolar defect.

Case report: A combined vertical and horizontal alveolar ridge augmentation was successfully achieved. Detailed clinical steps were described and demonstrated. The patient was rehabilitated with implant supported fixed partial denture with no pink ceramic. This two-staged procedure provides the amount of horizontal ridge width and vertical height to successfully place in the correct position the implants and achieve long term results.

Conclusions: Multicenter, randomised clinical trials are necessary to compare this procedure with other potential clinical solutions.

\section{KEYWORDS}

Bone defects, vertical ridge augmentation, horizontal ridge augmentation, guided bone regeneration 


\section{INTRODUCTION}

Bone augmentation procedures are routinely applied in cases of alveolar ridge deficiency in order to achieve optimal bone support for osseointegrated dental implants and ensure successful and long-term outcomes in dental implant therapy. Guided Bone Regeneration (GBR) was initially used to treat simple defects, including dehiscence and fenestration defects. ${ }^{1-4}$ The application of GBR for horizontal and vertical ridge augmentations is well documented 5-9 with high implant survival rates and low complication rates. ${ }^{10-12}$

Long term results concluded that vertically augmented bone using GBR techniques responds to implant placement in a similar fashion to native bone. . $^{13,14}$

The results of clinical and histologic studies of ridge augmentation with GBR indicated that anorganic bovine bonederived mineral (ABBM) mixed with autogenous particulate bone may be suitable material for staged localized ridge augmentation in both horizontal and vertical dimensions. ${ }^{7,9,9,13}$
This clinical report describes and demonstrates the successful use of autogenous particulate bone, anorganic bone mineral and barrier membranes to reconstruct severe alveolar bone defect.

\section{CASE PRESENTATION}

A healthy, non-smoker, 58-year-old male patient presented for an evaluation of his posterior left mandible, which had a history of implant placement with recurrent peri-implant infections. Significant clinical findings included several fistulous tracts (Figure1) and a periodontal depth of $10 \mathrm{~mm}$ around the implants (Figure 2). Radiographic examination was performed and revealed advanced periimplantitis with associated vertical bone loss (Figures 3,4,5).

Second left mandibular molar extraction as well as implants explantation was performed because the prognosis was poor (Figure 6,7)
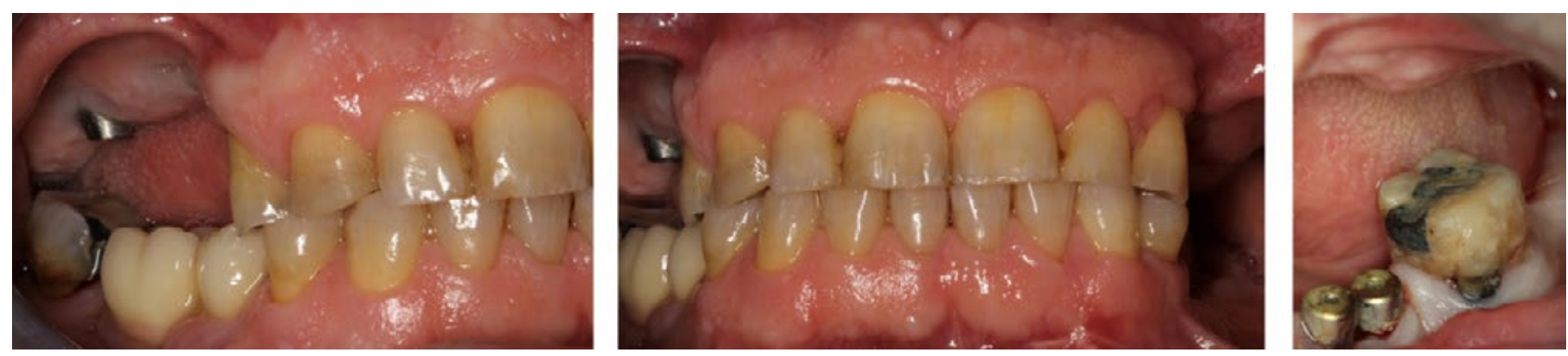

Figure 1. Intraoral findings (a) right lateral side; (b) Frontal view; (c) left lateral side
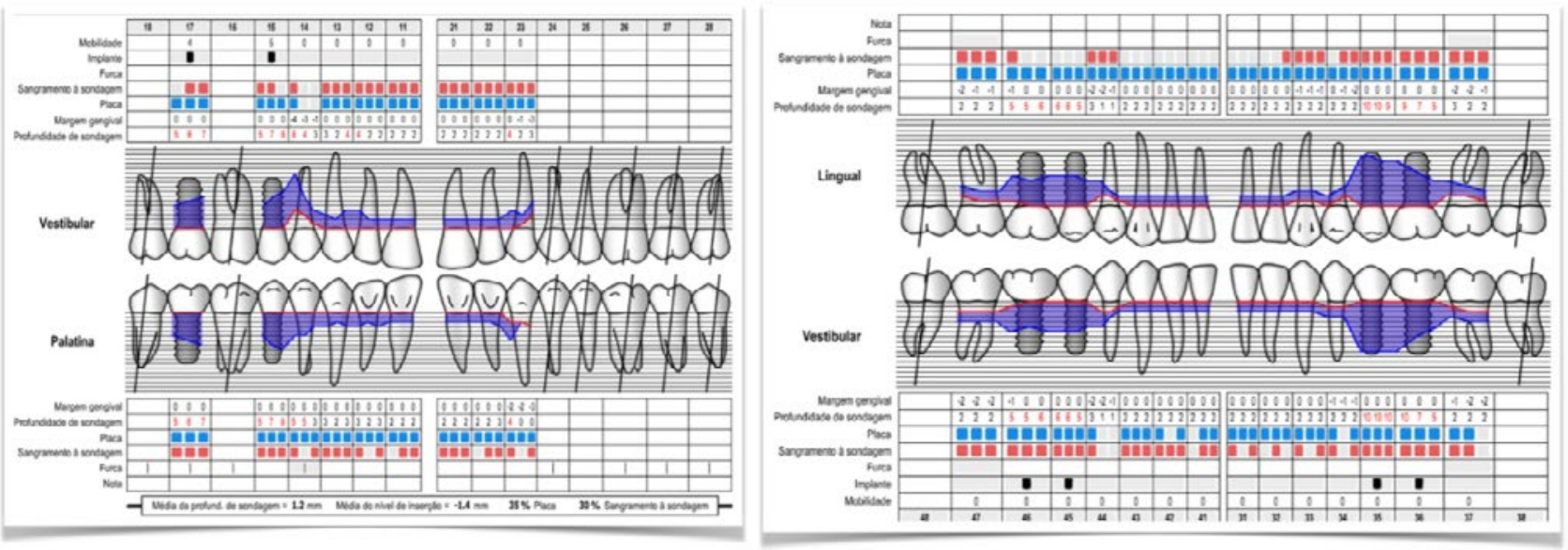

Figure 2. Periodontal Chart (Mean probing depth 1.2mm; Mean attachment level -1,4mm; 35\% Plaque; 30\% Bleeding on probing)



Figure 3. Panoramic x-ray 




Figure 4. 3D reconstruction of the severe maxillary and mandibular defects

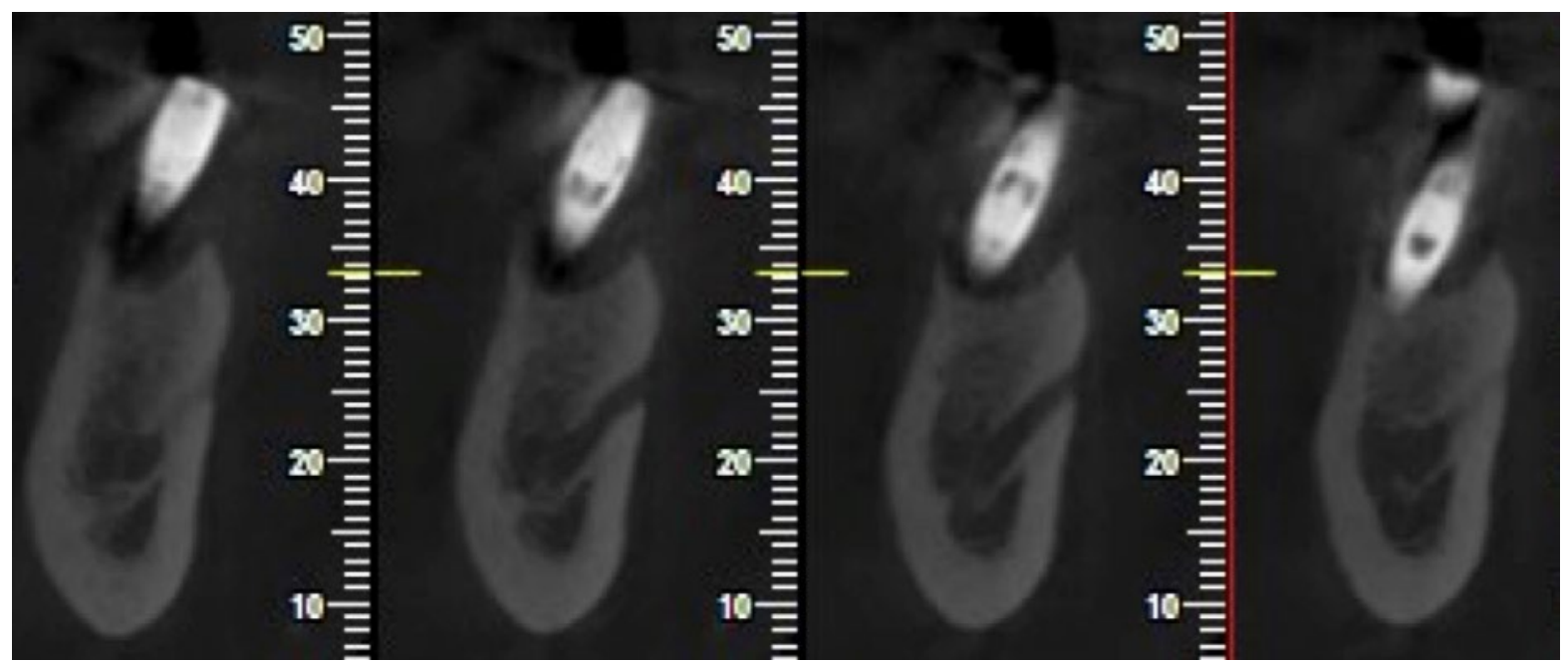

Figure 5. CBCT- Coronal section. Mandibular left posterior region. C\&H VI. Vertical defect over $9 \mathrm{~mm}$

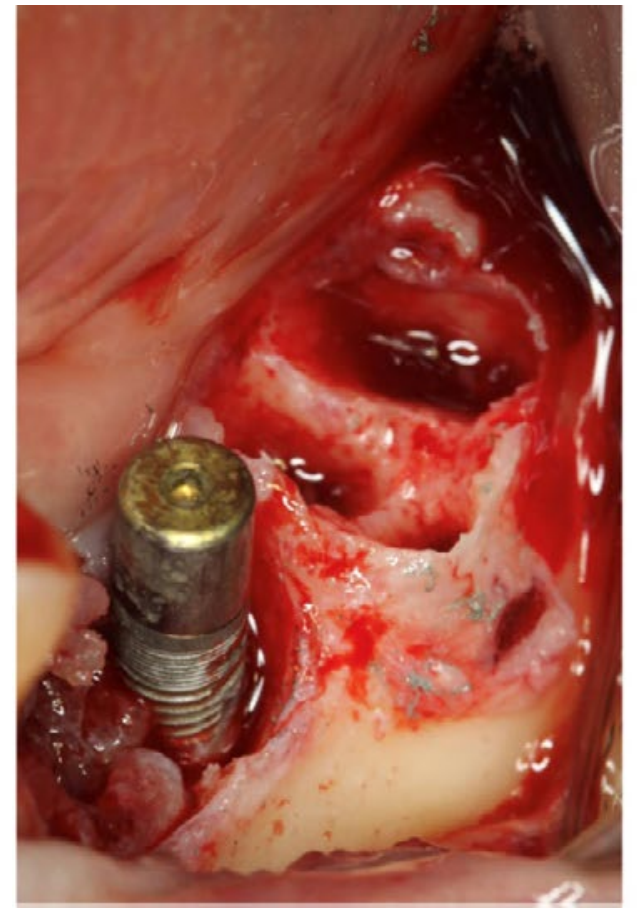

Figure 6. Atraumatic implants explantation

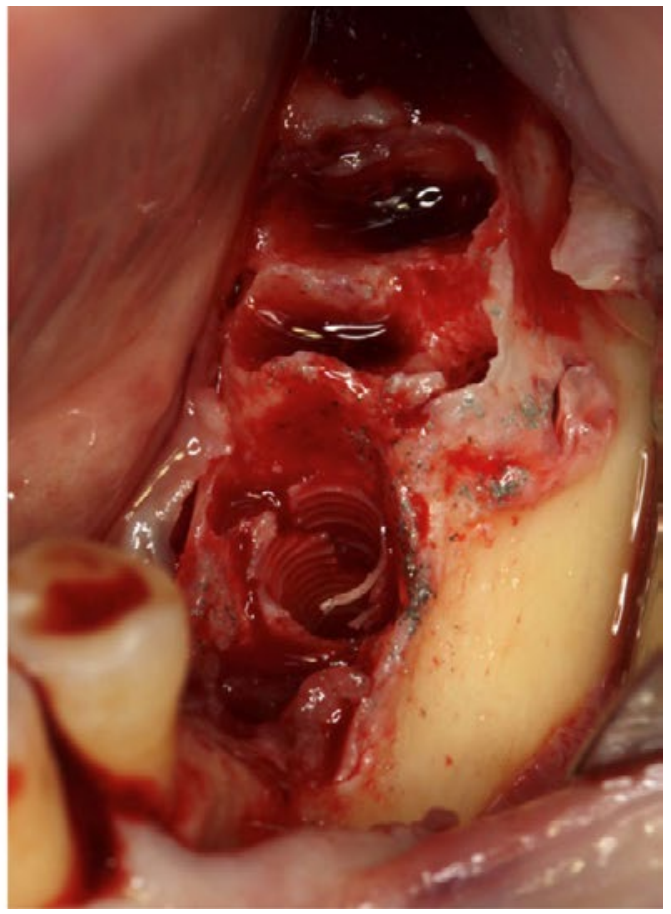

Figure 7. Molar extraction 
Following a 2-months healing period, a severe vertical ridge defect (9 mm height) was noted as expected (Figures 8,9).

The vertical defect significantly compromised the site to implant placement. The patient desired a fixed rehabilitation; therefore and after periodontal disease was controlled, the clinical plan was regenerate the alveolar defect tridimensional in order to ideally reconstruct form and function with a favourable implantcrown ratio and hygiene maintenance of the fixed prosthetic restoration.

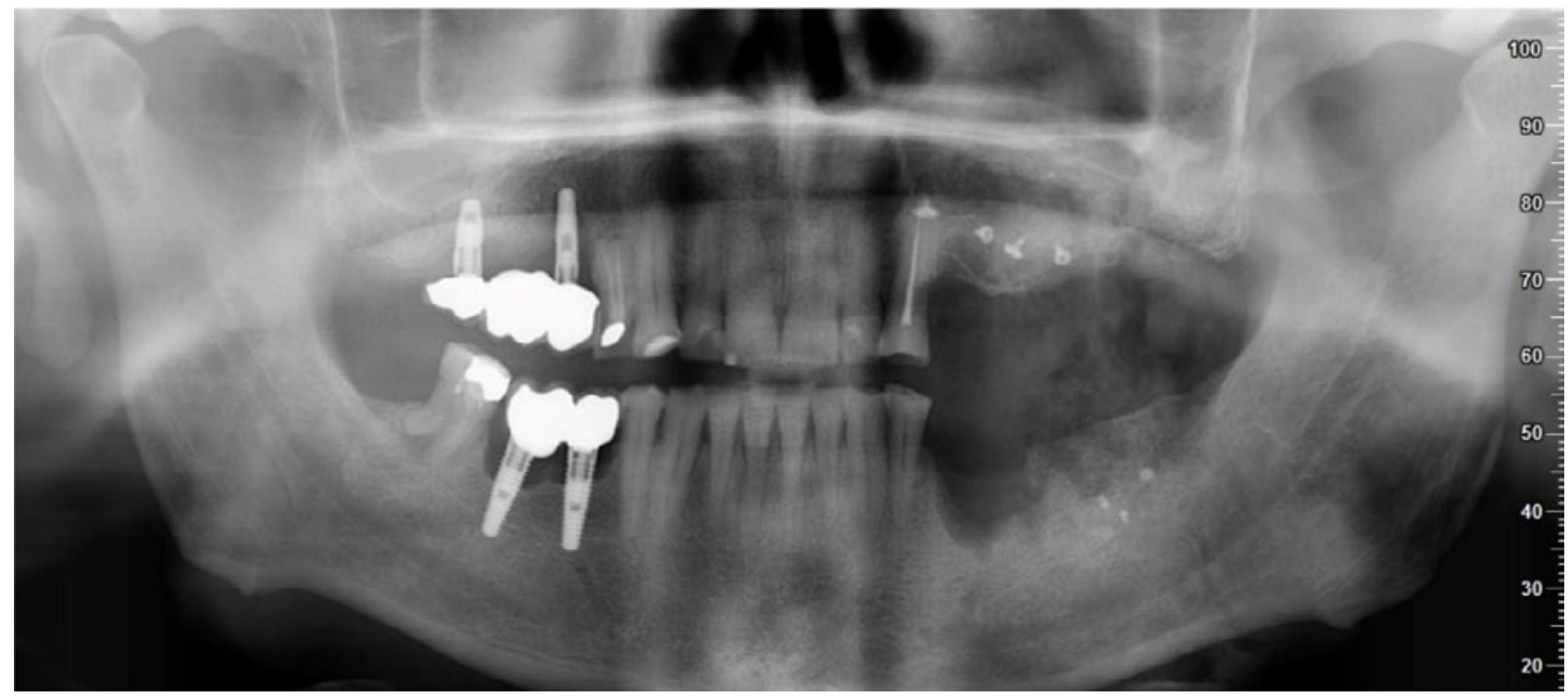

Figure 8. Panoramic $x$-ray after 2 months healing

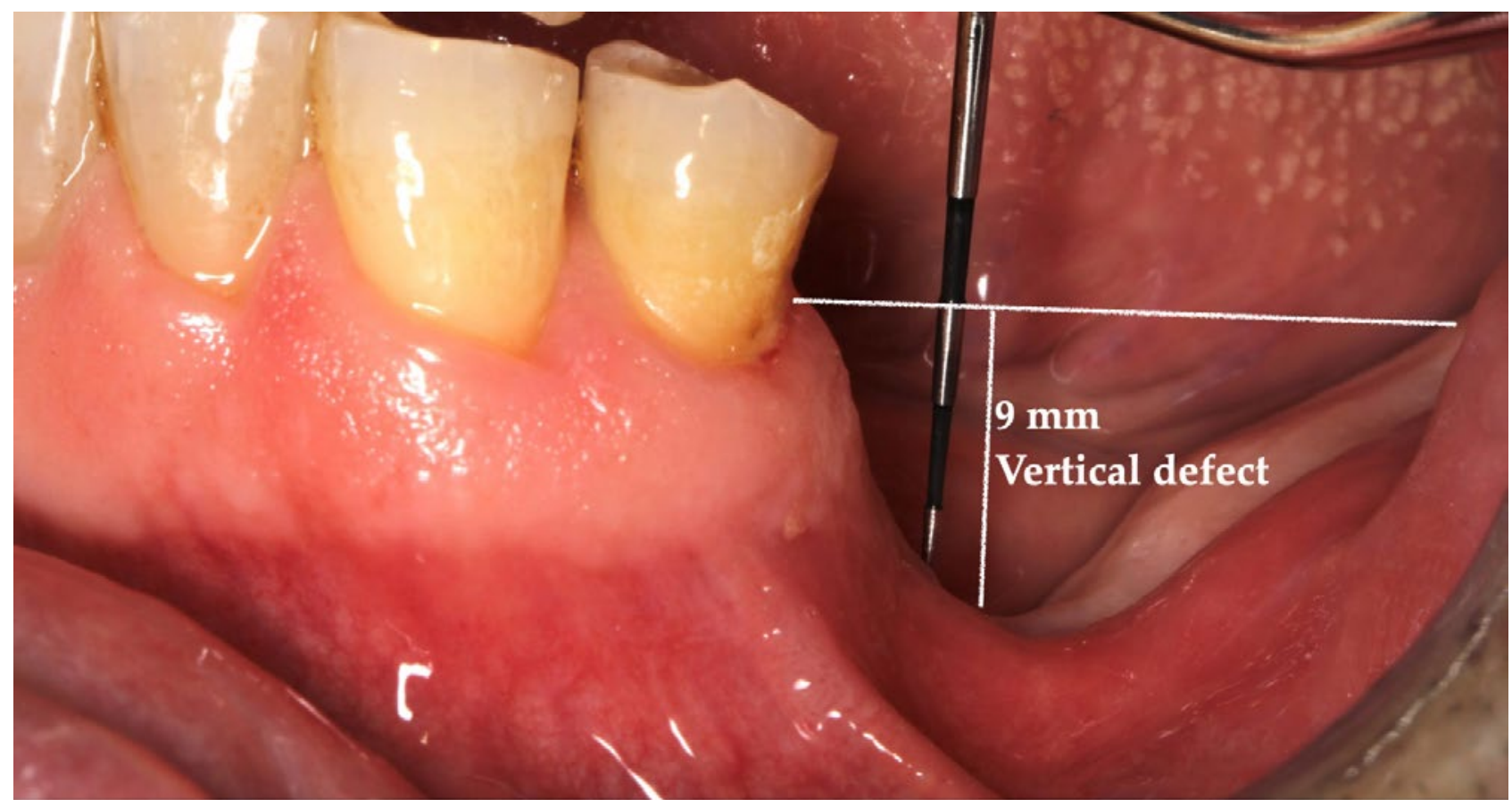

Figure 9. $9 \mathrm{~mm}$ vertical defect after 2 months post-extract second molar and implants explantation 


\section{SURGICAL PROCEDURE}

The patient was premedicated with amoxicillin $2 \mathrm{gr} 1$ hour before surgery and was given $1 \mathrm{gr}$ penicillin 2 times a day for 1 week following surgery.

The patient rinsed with $0.12 \%$ chlorhexidine solution (Eludril,
Pierre Fabre Oral Care, France) for 1 minute prior to surgery and the tongue was scrapped (Figure10).

The patient's skin surrounding the surgical site was disinfected, and a sterile surgical drape was applied to minimize potential contamination from extraoral sources (Figure11).

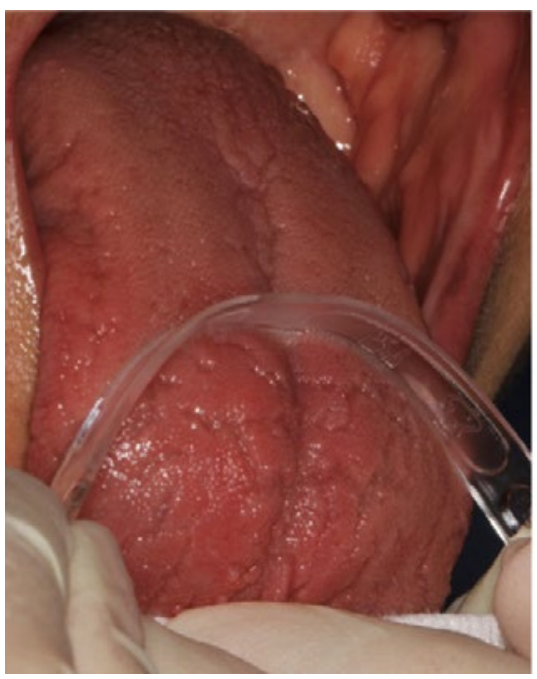

Figure 10. Tongue scrapping and mouth rinse with chlorhexidine $0,12 \%$



Figure11. Surgical drape placed over patient skin disinfection
A full thickness, midcrestal incision was made in the keratinised gingiva on the alveolar crest, within $2 \mathrm{~mm}$ of the retromolar pad and for adequate surgical access, a distal oblique vertical incision toward coronoid mandibular process (Figure12).

A vertical incision was made mesiobuccally two teeth away and a 3-4 $\mathrm{mm}$ mini incision is placed at the mesio-lingual line angle of the most distal tooth. Retromolar pad is gently elevated, lifted and incorporates lingual flap.

After primary incisions were made, periosteal elevators were used to reflect a full thickness flap beyond the mucogingival junction and at $5 \mathrm{~mm}$ beyond the bone defect (Figure 13)

The lingual flap was elevated to the mylohyoid line (high mylohyoid line) (Figure 14) and carefully separated from the ascending fibres of mylohyoid muscle (Figure 15).

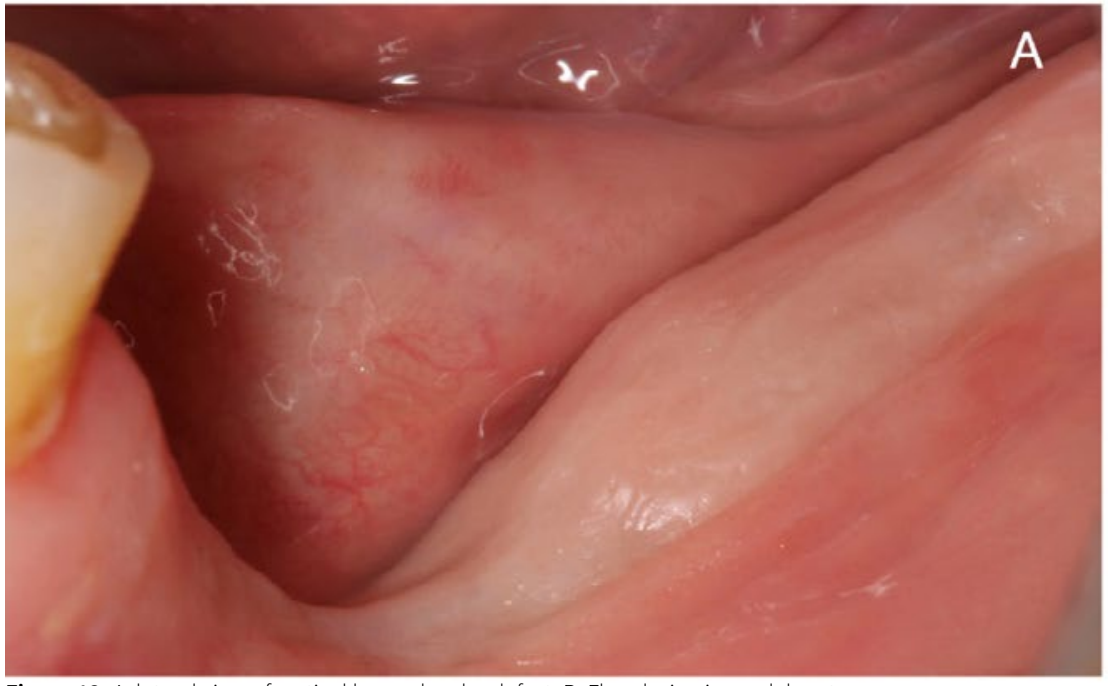

Figure 12. A. lateral view of vertical bone alveolar defect. B. Flap design in model cast

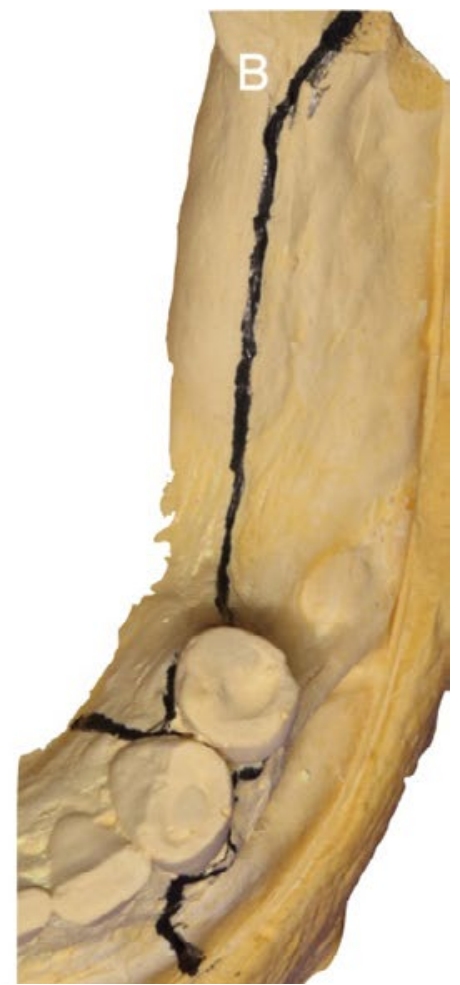


68 | JSPIR

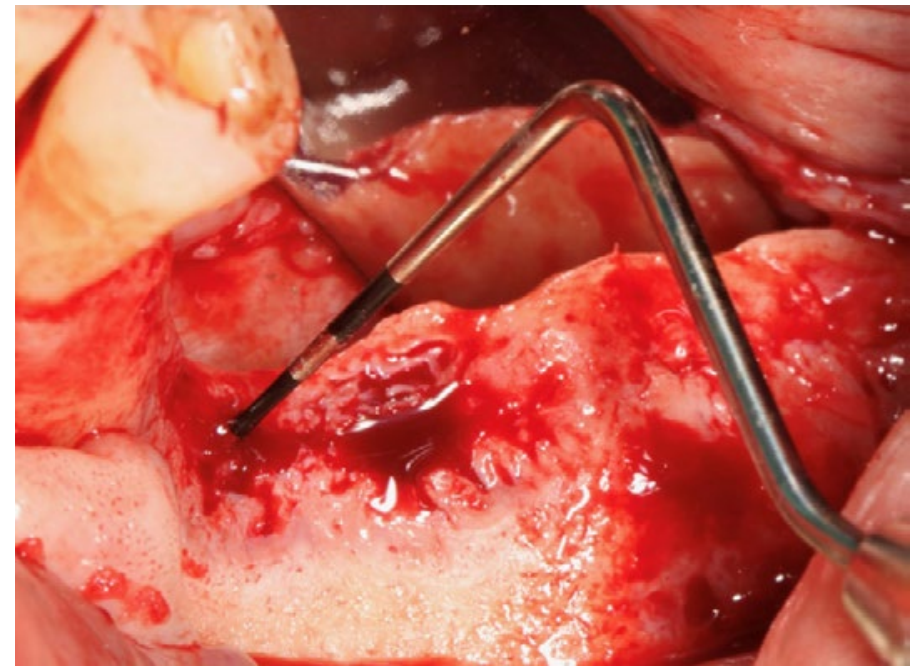

Figure 13. Exposed bone cleaned of all soft tissue remnants

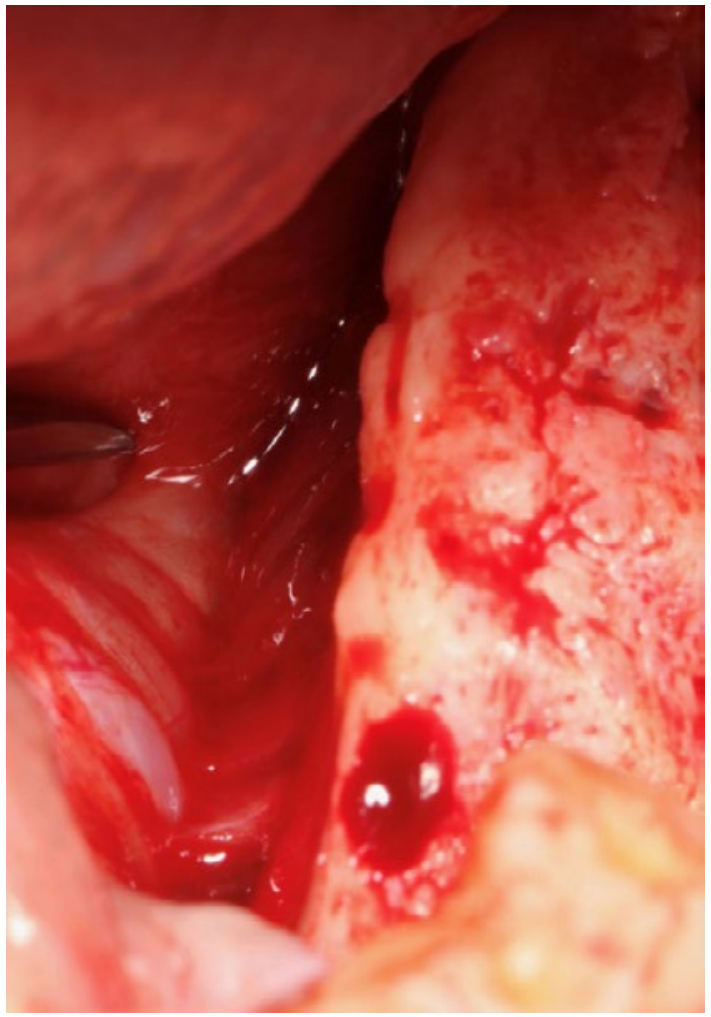

Figure 14. Elevation of lingual flap to the mylohyoid line.

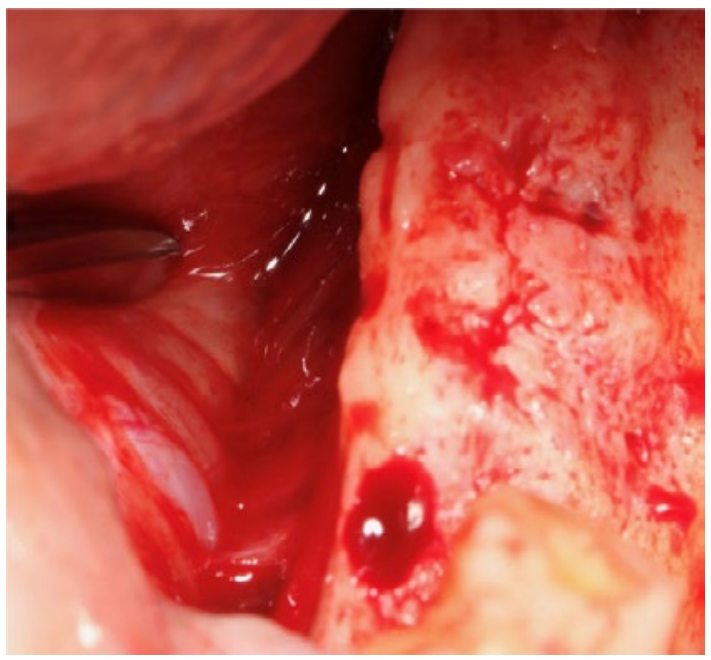

Figure 15. Mylohyoid blunt separation 
The exposed bone was cleaned of all soft tissue remnants; An appropriate sized, titanium-reinforced dense polytetrafluoroethylene non-resorbable membrane (d-PTFE; Cytoplast $^{\circ}$ Ti-250, Osteogenics Biomedical, Inc., Lubbock, Texas) was selected and trimmed to totally cover the graft volume. With a small bur, the recipient bony bed was prepared with multiple decorticate holes to expose the medullary space (Figures 16,17). Autogenous bone was harvested from the left mandibular ascending ramus with Safescrapper twist curved ${ }^{\circ}$ (Figure 18).

The autogenous bone was mixed with ABBM (Bio-Oss ${ }^{\circ}$, Geistlich Pharma AG, Wolhusen, Switzerland) (Figure19).
The membrane was fixated first on the lingual side using multiple pins (Master Pin control fixation", Meisinger, Neuss, Germany) (Figure 20). The autogenous particulate composite graft was placed appositionally in the vertical alveolar defect and the membrane was folded over onto the buccal alveolus and fixated with additional titanium pins (Figure 21). The medial border was placed $3 \mathrm{~mm}$ from the distal surface of first left premolar ${ }^{34}$ to prevent membrane exposure. A resorbable collagen membrane (Biogide", Geistlich Pharma AG, Wolhusen, Switzerland) was applied to protect and contain apically the graft and minimize postoperative complications (Figure 21).

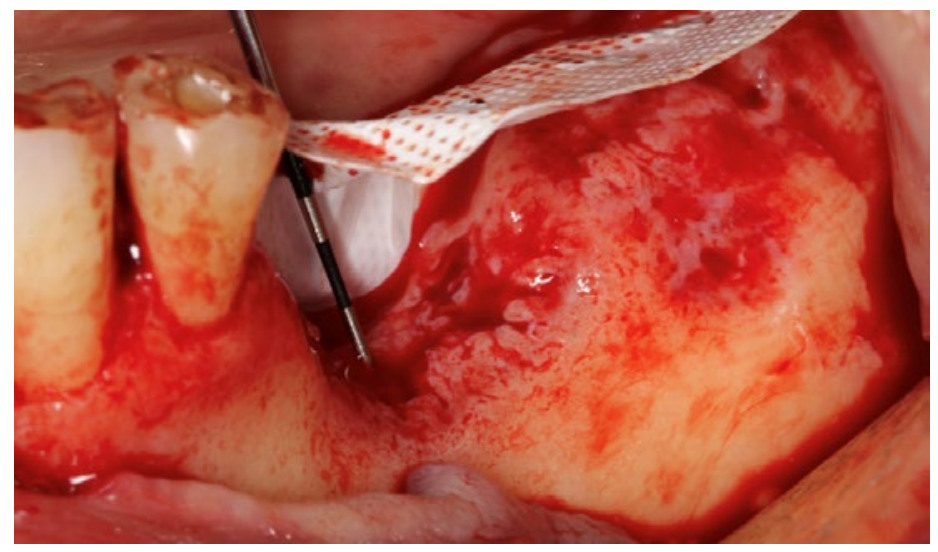

Figure 16. Selection and trim of d-PTFE membrane

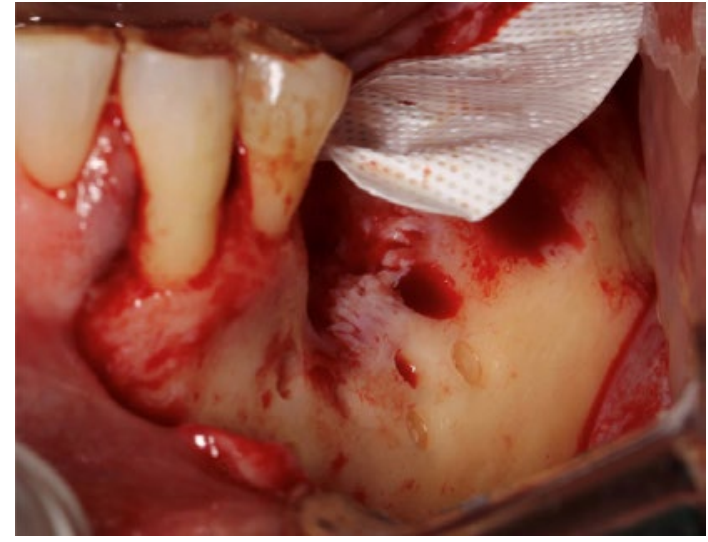

Figure 17. Multiple decorticalization screw holes

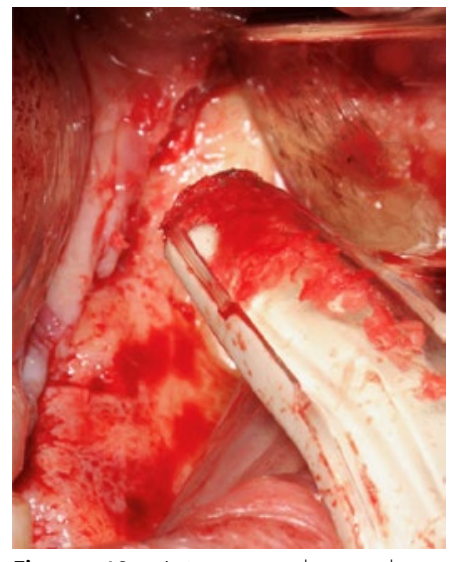

Figure 18. Autogenous bone shaves collected with Safescrapper



Figure 19. 1:1 ratio of autograft mixed with ABBM (Bio-Oss" , Geistlich Pharma AG, Wolhusen, Switzerland)

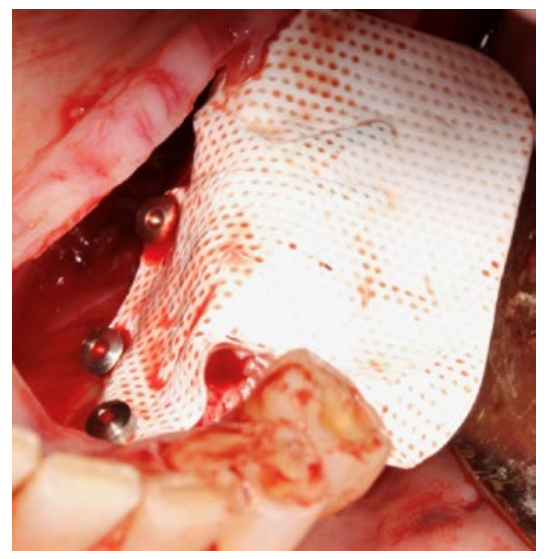

Figure 20. d-PTFE membrane (Cytoplast", Osteogenics) 1:1 ratio of autograft mixed with ABBM

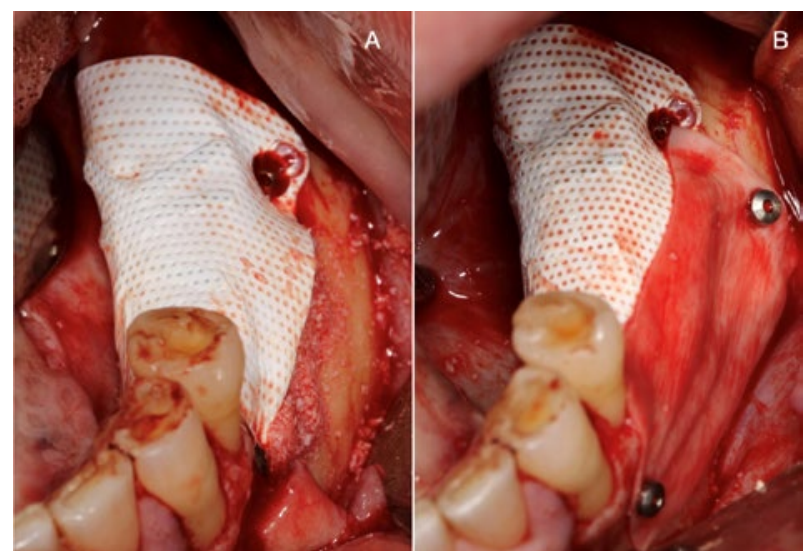

Figure 21. A. Buccal view of the d-PTFE membrane secured with pins; B. complete immobilisation of the graft is achieved 
The lingual flap advancement at the "deep" mylohyoid attachment was made with an a horizontal "hockey stick" periosteal incision with the blade tip sweeping through periosteum (Figure22). Advancement of all three zones of the lingual flap allows a completely relaxed lingual flap (Figure 23,24).

Periosteal releasing incisions at buccal flap were performed to provide adequate flap reflection for tension free primary closure (Figure 25,26)

The flap was closed in two layers with the use of horizontal mattress (Cytoplast PTFE suture", Osteogenics, 3-0) and single interrupted sutures (Supramid ${ }^{\circ}$, B Braun Medical, 4-0) (Figures
27,28). Medications were followed as described earlier. In addition, an anti-inflammatory medication, 600 mg ibuprofen arginate was prescribed two times a day for five days. For chemical plaque control, $0,12 \%$ chlorhexidine solution was used three times a day from 24 hours post-surgery until the time of suture removal. Postoperative swelling was significant, reaching maximum at 48 hours; swelling disappeared completely after twelve days. Discomfort was referred and was associated with tension from the swelling. Pain was minimal. No other symptoms occurred during post-surgical period. No removable appliance was used to avoid trauma.

After nine months of uneventful healing, it was performed a

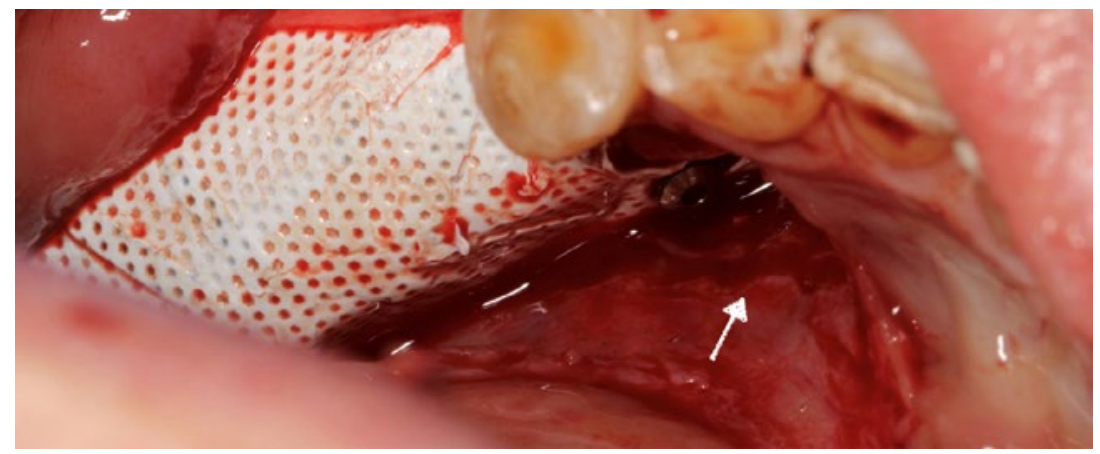

Figure 22. Modified lingual flap advancement: "deep" mylohyoid attachment (“hockey stick" periosteal incision)

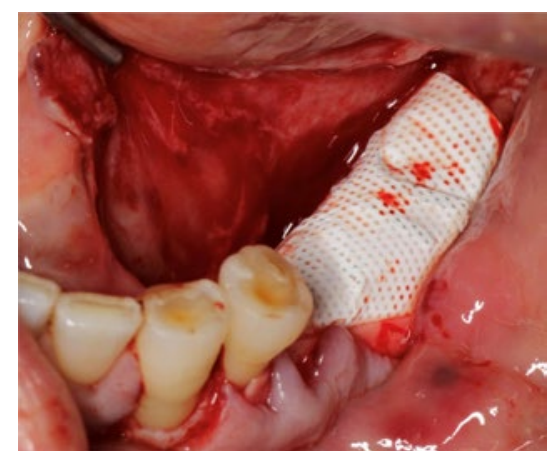

Figure 23. Modified lingual flap advancement concluded

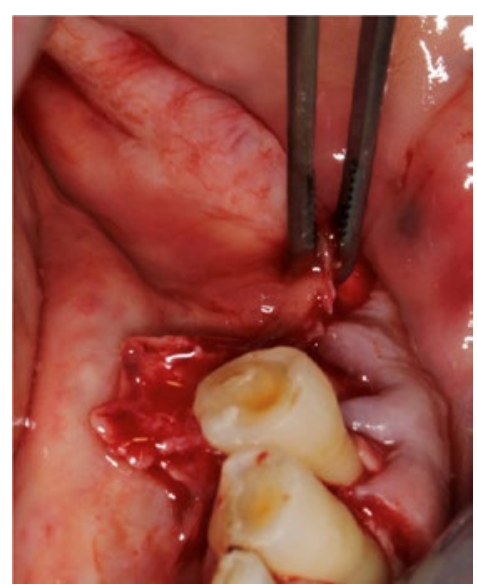

Figure 24. Flexibility and tension-free of lingual flap after detachment

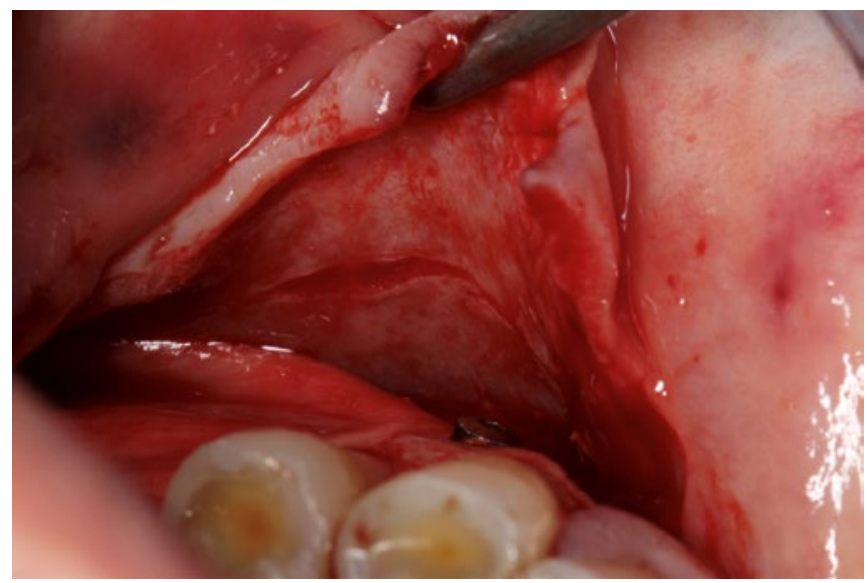

Figure 25. Buccal flap advancement

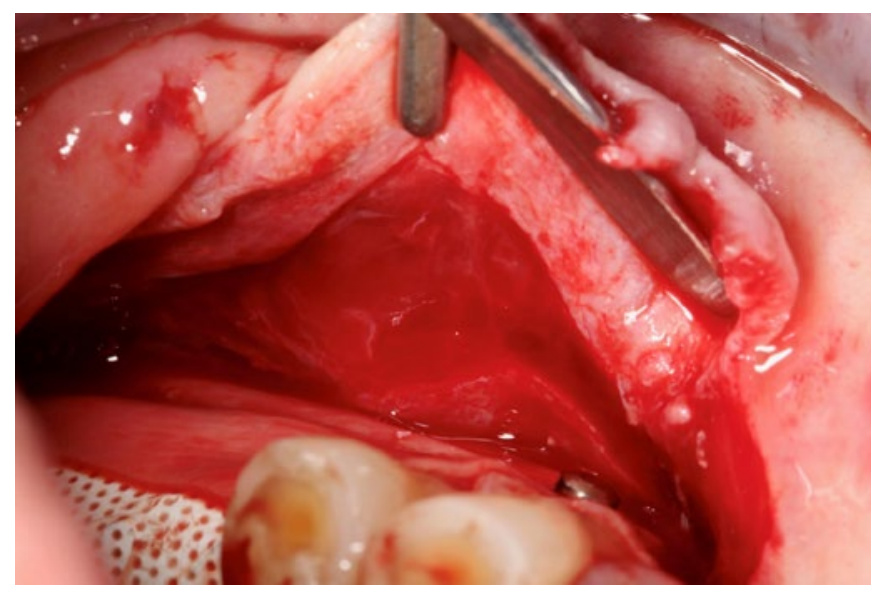

Figure 26. Subperiosteal bundles and elastic fiber separation

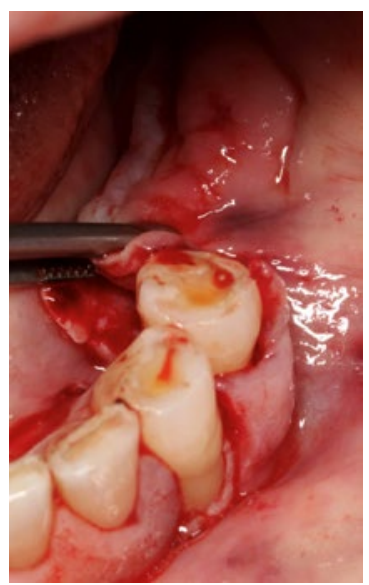

Figure 27. Tension free primary closure

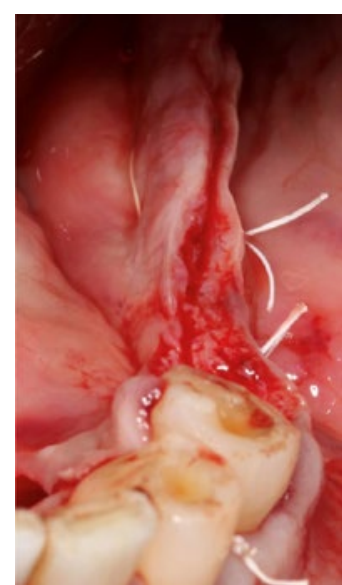

Figure 28. Double layer suture 
radiographic examination (Cone Beam Computed Tomography - CBCT) which revealed a vertical bone gain of $9.31 \mathrm{~mm}$ and 11.1 $\mathrm{mm}$ in premolar and molar left mandibular regions (Figure 29). The area was opened using the same full-thickness flap design. The membrane had maintained its original position, and bone growth was evident (Figure 30). After removal of the titanium pins and the d-PTFE, complete vertical bone regeneration was observed (Figures 31,32,33).

Two BTI Implants were placed (BTI'-Biotechnology Institute S.L., Vitoria, Spain) in accordance with the manufacturer's protocol
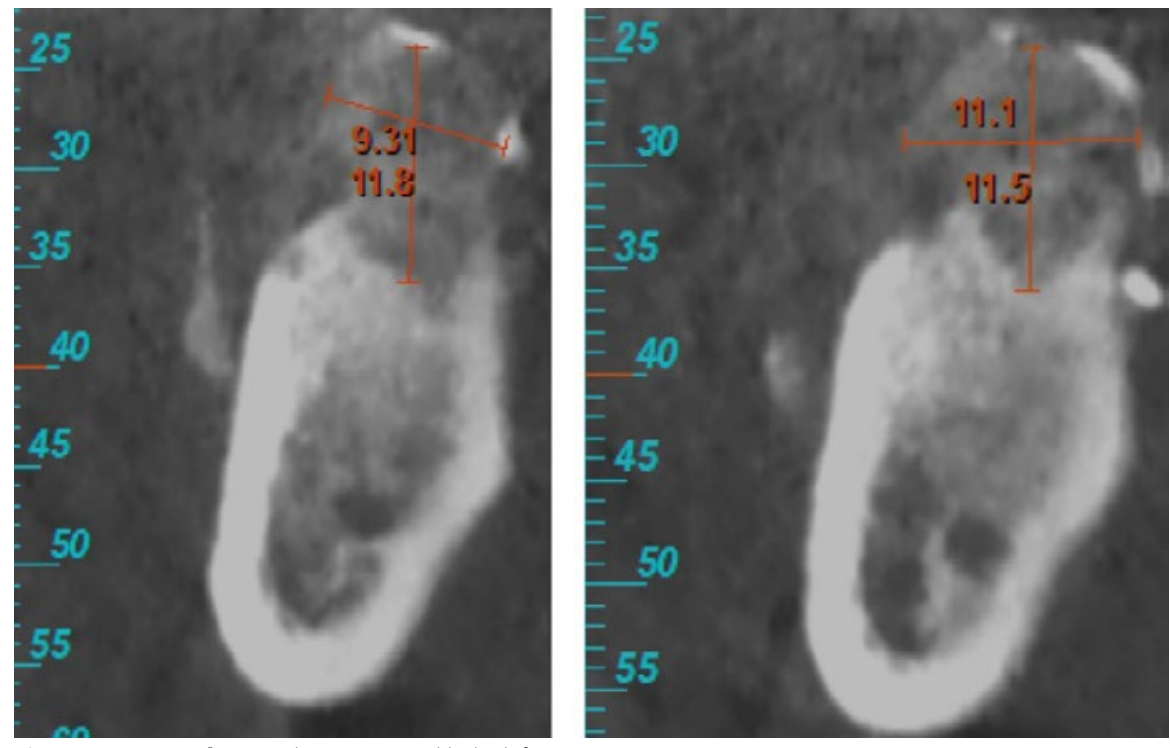

Figure 29. BTI Scan"- coronal section. Mandibular left posterior region

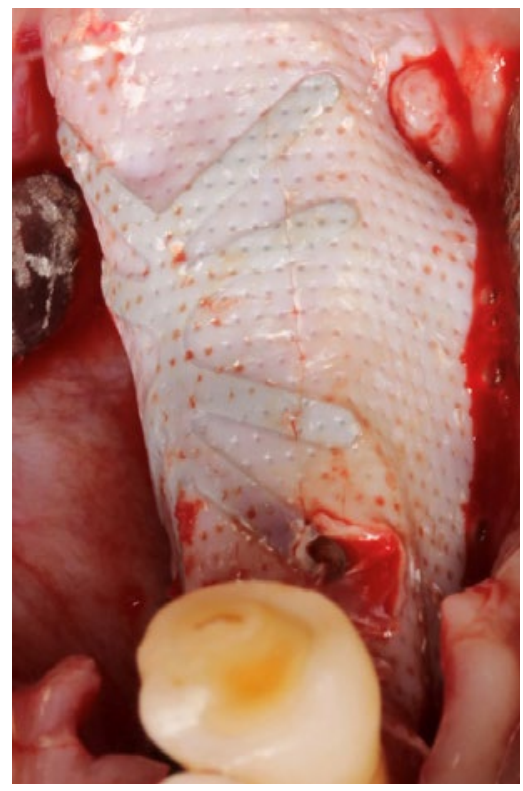

Figure 30. No soft tissue ingrowth under the adapted membrane

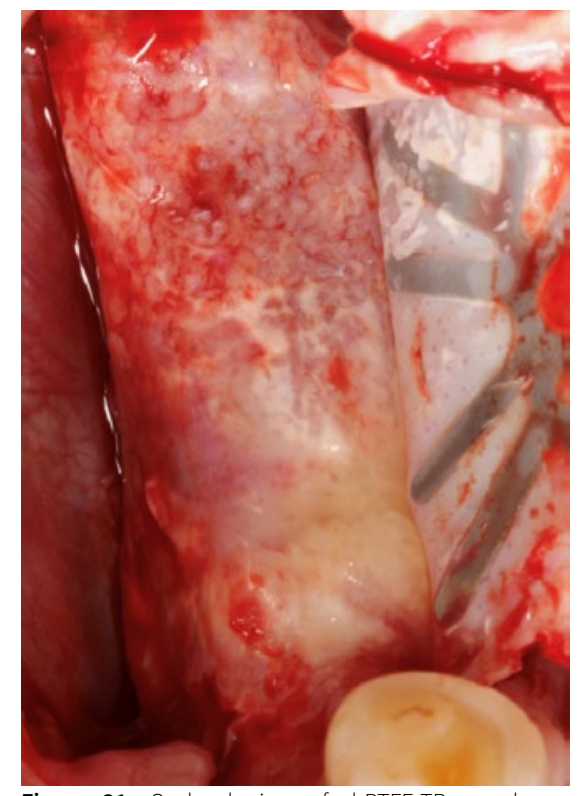

Figure 31. Occlusal view of d-PTFE-TR membrane removal and revelation of baby bone

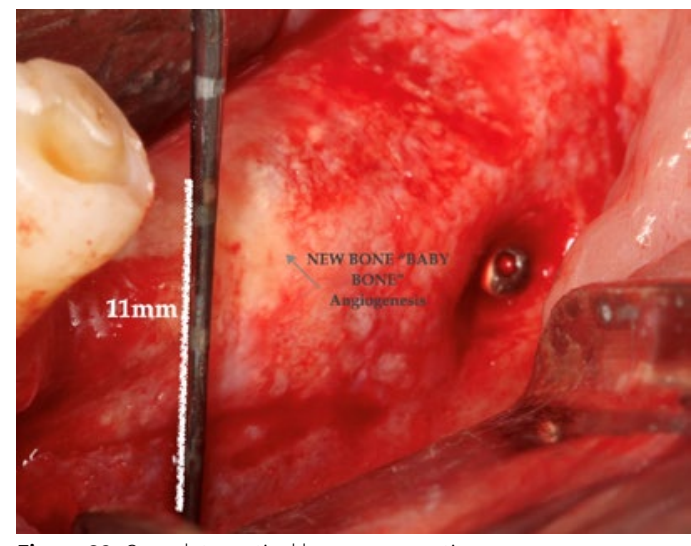

Figure 32. Complete vertical bone regeneration
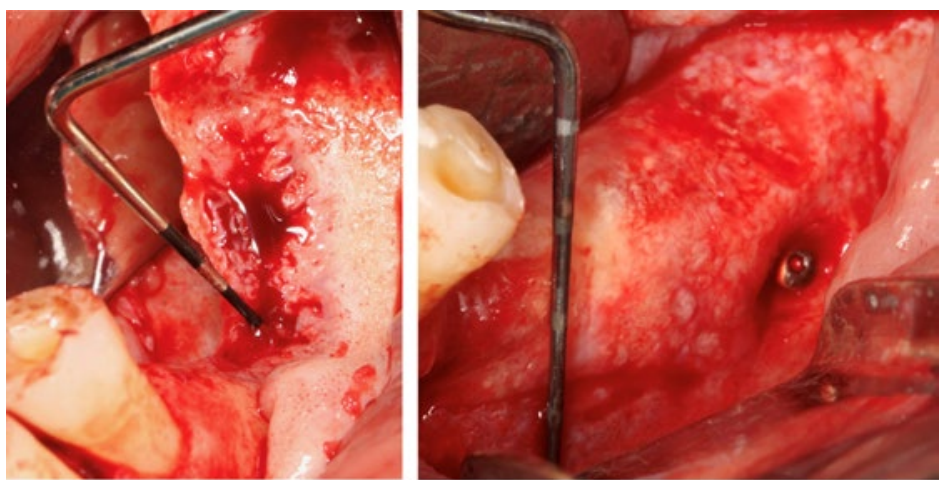

Base Line

Figure 33. Initial clinical situation and after nine months 

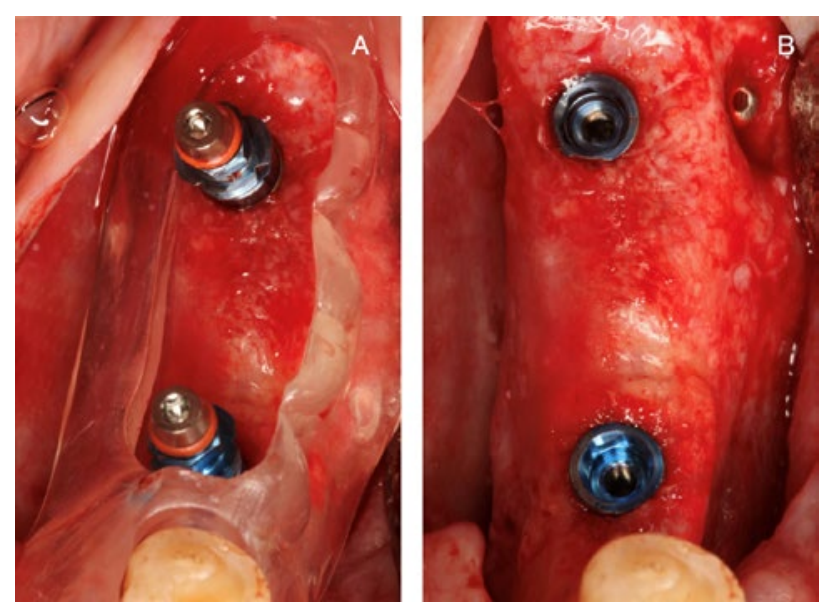

Figure 34 A, B. Occlusal view of implants placed into the newly formed bone and with surgical guidance (Figure 34). After implant placement, a protective microsausage with $70 \%$ ABBM and $30 \%$ autogenous bone was placed on top of implants over the newly formed crestal bone to protect the graft from possible early remodelling (Figures 35A, 35B, 35C).

The implants were submerged through a 2-stage technique for 6 months. After 3.5 months a soft tissue augmentation was done (free gingival graft-strip technique) to gain soft tissue volume and keratinised tissue (Figure 36). After 2.5 more months the implants were uncovered (Figure 37 ) and restored (Figure 38C) with a splinted three-unit implant supported fixed partial denture with no pink ceramic (Figure $38 \mathrm{~A}, \mathrm{~B}$ ). The patient was entered into a scheduled maintenance program that included a clinical examination every six months and annual radiographic examination.
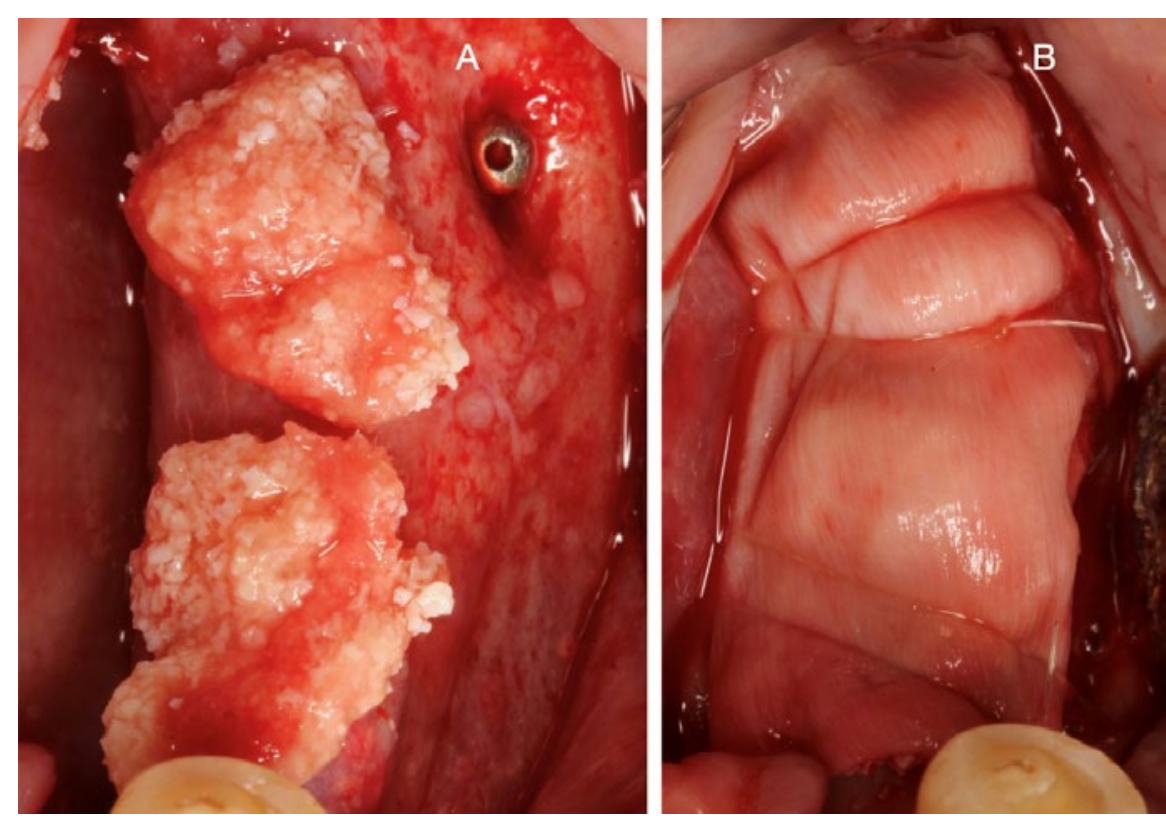

Figure 35. A-Protective sausage (70\% ABBM/ 30\% autogenous bone); B- micro sausage stabilised with periosteal resorbable sutures.

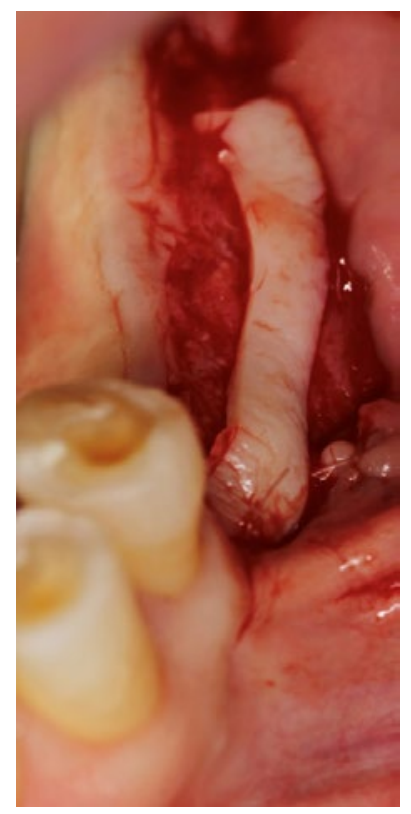

Figure 36. Free gingival graft with strip technique

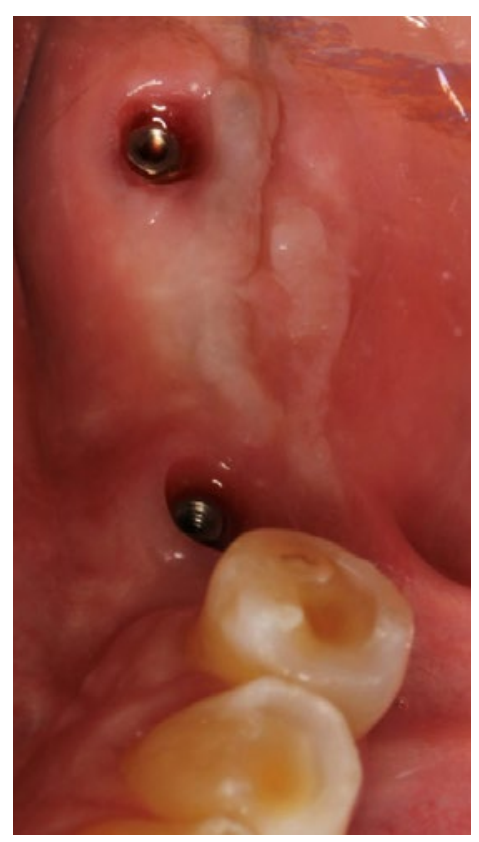

Figure 37. Implant uncover after 2.5 months


Figure 38. A- Peri-apical radiograph after 14 months of loading; B- ceramic fixed partial implant supported denture; C- Final restoration in function 


\section{DISCUSSION AND CONCLUSION}

Vertical ridge augmentation (VRA) is one of the greatest challenges for bone in implant therapy; it is biologically demanding, as angiogenesis must reach a certain distance from existing bone to new bone can be formed. ${ }^{15,16}$

On the other hand, VRA is technique sensitive and complications intra and post-operative can occur. ${ }^{17,18}$ However, in cases with limited bone availability for placing short implants, or due to restorative considerations, VRA offers the possibility to augment lost bony structures and improves aesthetic outcomes. ${ }^{19}$

Long term studies concluded that vertically augmented bone using GBR techniques responds to implant placement in a similar fashion to native bone; is safe and predictable, with minimal complications. $.13,14,20$

The case presented describes a detailed protocol for a patient treated with vertical ridge augmentation in the posterior mandible with a severe defect of alveolar ridge and demonstrates how is possible to reach predictable significant vertical bone regeneration $(9 \mathrm{~mm}$ and $11 \mathrm{~mm}$ in premolar and molar region, respectively). Autogenous particulate bone and ABBM were used for VRA with a dense-PTFE titanium reinforced non-resorbable membrane; implants were placed 9 months after uneventful healing. This two-staged procedure provides the amount of horizontal ridge width and vertical height to successfully place in the correct position the implants and achieve long term results. Continued follow-up will be mandatory to investigate the stability of the newly regenerated bone around the implants over time. Multicenter, randomised clinical trials are necessary to compare this procedure with other potential clinical solutions.

\section{CONFLICT OF INTEREST}

The author declared that there is no conflict of interest.

\section{REFERENCES}

1. 1. Albrektsson T, Zarb G, Worthi Albrektsson T, Zarb G, Worthington P, Eriksson AR. The long-term efficacy of currently used dental implants: a review and proposed criteria of success. Int J Oral Maxillofac Implants. 1986 Summer;1(1):11-25.

2. Buser D, Brägger U, Lang NP, Nyman S. Regeneration and enlargement of jaw bone using guided tissue regeneration. Clin Oral Implants Res. 1990 Dec;1(1):22-32.

3. Dahlin C, Andersson L, Linde A. Bone augmentation at fenestrated implants by an osteopromotive membrane technique. A controlled clinical study. Clin Oral Implants Res. 1991 Oct-Dec;2(4):159-65.

4. Jovanovic SA, Spiekermann H, Richter EJ. Bone regeneration around titanium dental implants in dehisced defect sites: a clinical study. Int J Oral Maxillofac Implants. 1992 Summer;7(2):233-45.

5. Buser D, Ingimarsson S, Dula K, Lussi A, Hirt HP, Belser UC. Long-term stability of osseointegrated implants in augmented bone: a 5-year prospective study in partially edentulous patients. Int J Periodontics Restorative Dent. 2002 Apr;22(2):109-17.

6. Zitzmann NU, Schärer P, Marinello CP. Long-term results of implants treated with guided bone regeneration: a 5-year prospective study. Int J Oral Maxillofac Implants. 2001 May-Jun;16(3):355-66.

7. Urban IA, Nagursky H, Lozada JL. Horizontal ridge augmentation with a resorbable membrane and particulated autogenous bone with or without anorganic bovine bone-derived mineral: a prospective case series in 22 patients. Int J Oral Maxillofac Implants. 2011 Mar-Apr;26(2):404-14.

8. Urban IA, Nagursky H, Lozada JL, Nagy K. Horizontal ridge augmentation with a collagen membrane and a combination of particulated autogenous bone and anorganic bovine bone-derived mineral: a prospective case series in 25 patients. Int J Periodontics Restorative Dent. 2013 May-Jun;33(3):299-307.

9. Urban IA, Lozada JL, Jovanovic SA, Nagursky H, Nagy K. Vertical ridge augmentation with titanium-reinforced, dense-PTFE membranes and a combination of particulated autogenous bone and anorganic bovine bone-derived mineral: a prospective case series in 19 patients. Int J Oral Maxillofac Implants. 2014 Jan-Feb;29(1):185-93.

10. Hämmerle CH, Jung RE, Feloutzis A. A systematic review of the survival of implants in bone sites augmented with barrier membranes (guided bone regeneration) in partially edentulous patients. J Clin Periodontol. 2002;29 Suppl 3:226-31; discussion 232-3.

11. Aghaloo TL, Moy PK. Which hard tissue augmentation techniques are the most successful in furnishing bony support for implant placement? Int J Oral Maxillofac Implants. 2007;22 Suppl:49-70. Erratum in: Int J Oral Maxillofac Implants. 2008 Jan-Feb;23(1):56.

12. Esposito M, Grusovin MG, Coulthard P, Worthington HV. The efficacy of various bone augmentation procedures for dental implants: a Cochrane systematic review of randomized controlled clinical trials. Int J Oral Maxillofac Implants. 2006 Sep-Oct;21(5):696-710.

13. Urban IA, Jovanovic SA, Lozada JL. Vertical ridge augmentation using guided bone regeneration (GBR) in three clinical scenarios prior to implant placement: a retrospective study of 35 patients 12 to 72 months after loading. Int J Oral Maxillofac Implants. 2009 May-Jun;24(3):502-10.

14. Simion M, Jovanovic SA, Tinti C, Benfenati SP. Long-term evaluation of osseointegrated implants inserted at the time or after vertical ridge augmentation. A retrospective study on 123 implants with 1-5 year follow-up. Clin Oral Implants Res. 2001 Feb;12(1):35-45.

15. Urban IA, Montero E, Monje A, Sanz-Sánchez I. Effectiveness of vertical ridge augmentation interventions: A systematic review and meta-analysis. J Clin Periodontol. 2019 Jun;46 Suppl 21:319-339.

16. Wikesjö UM, Kean CJ, Zimmerman GJ. Periodontal repair in dogs: supraalveolar defect models for evaluation of safety and efficacy of periodontal reconstructive therapy. J Periodontol. 1994 Dec;65(12):1151-7.

17. Fontana F, Maschera E, Rocchietta I, Simion M. Clinical classification of complications in guided bone regeneration procedures by means of a nonresorbable membrane. Int J Periodontics Restorative Dent. 2011 Jun;31(3):265-73.

18. Rocchietta I, Fontana F, Simion M. Clinical outcomes of vertical bone augmentation to enable dental implant placement: a systematic review. J Clin Periodontol. 2008 Sep;35(8 Suppl):203-15.

19. Salvi GE, Monje A, Tomasi C. Long-term biological complications of dental implants placed either in pristine or in augmented sites: A systematic review and metaanalysis. Clin Oral Implants Res. 2018 Oct;29 Suppl 16:294-310.

20. Urban IA, Monje A, Lozada JL, Wang HL. Long-term Evaluation of Peri-implant Bone Level after Reconstruction of Severely Atrophic Edentulous Maxilla via Vertical and Horizontal Guided Bone Regeneration in Combination with Sinus Augmentation: A Case Series with 1 to 15 Years of Loading. Clin Implant Dent Relat Res. 2017 Feb;19(1):46-55 